\title{
Preconditioning improves bleaching susceptibility in the reef-building coral Pocillopora acuta through modulations in autophagy pathway
}

\author{
Eva Majerova ${ }^{1}$, Fiona Carey $^{1}$, and Ruth Gates ${ }^{1,2}$ \\ ${ }^{1}$ University of Hawai'i at Mānoa Hawaii Institute of Marine Biology \\ ${ }^{2}$ University of Hawaii at Manoa
}

May 5, 2020

\begin{abstract}
Stony corals heavily rely on their intracellular algal symbionts for energetical supply. Increasing extreme weather driven by climate change often leads to disruption of the symbiosis and to coral death, threatening the sole existence of coral reefs, the key underwater ecosystems. As climate change mitigation outcomes are uncertain, it is important to search for ways to increase coral resilience towards future climate conditions, thermal extremes in particular. It has been shown that corals can withstand stress conditions better after previous exposure, but the mechanism remains unclear. Here we show that after threeday thermal preconditioning, stony coral Pocillopora acuta becomes more resilient to acute heat stress through modulations in cell signaling. In preconditioned corals, the expression of pro-survival gene pBcl-2 increases relatively to pro-death genes pBak and pBax during thermal stress, and the coral bleaching rate significantly decreases. After pBcl-2 activity inhibition, preconditioned corals lose the acquired beneficial phenotype and bleach at the same rate as non-preconditioned corals, which confirms the crucial role of programmed cell death in coral bleaching and acclimatization. The detailed analysis points to the involvement of autophagy/symbiophagy rather than apoptosis in the process. A similar shift in gene expression also occurs in thermally stressed corals that have previously acclimatized to summer temperatures in Kaneohe Bay, Hawai'i, suggesting that corals can naturally increase their resilience to warming events during high-risk periods through alterations in cell signaling. An in-depth understanding of molecular mechanisms underlying coral acclimatization and resilience could open the way for restoration practices such as human-assisted evolution.
\end{abstract}

\section{Keywords}

Stony corals, coral bleaching, autophagy, programmed cell death, assisted evolution, acclimatization

\section{Introduction}

Reef building stony corals live in a mutually beneficial partnership with photosynthetic algae that provide them with essential nutrients and oxygen. Stressful conditions such as high temperature or oceanic acidification lead to the disruption of symbiosis known as coral bleaching, and eventual coral death. Climate-change related thermal mass bleaching events have become increasingly common, affecting about $75 \%$ of coral reefs in Hawaii and $93 \%$ of surveyed corals in Great Barrier Reef, with over 50\% mortality in some regions (Couch et al., 2017; Hoegh-Guldberg et al., 2015). Current climate-change mitigation measures (e.g. the Paris agreement), aiming to limit global warming to 2, seem not being aggressive enough to effectively moderate impacts on coral reefs, leaving these ecosystems under an imminent threat of collapsing and disappearing by 2050 (Ainsworth et al., 2016; Frieler et al., 2013). 
Coral reefs are of particular importance for life on Earth. They produce atmospheric oxygen - while absorbing carbon dioxide - through their photosynthesizing symbiotic algae, they also offer necessary shelter for marine life, serve as nurseries for fishery species, protect coastal regions from wave exposure and provide food for more than 3 billion people (Vercelloni et al., 2018). The World Wildlife Fund for Nature estimates that the range of products and services that coastal and marine environments provide can be valued conservatively at $\$ 2.5$ trillion each (Hoegh-Guldberg et al., 2015). So, not surprisingly, searching for ways to better protect coral reefs became the kernel of coral research all over the world.

Animals and plants are known to acclimatize to stress conditions and several recent studies show that heat acclimatization might help corals better withstand thermal stress and reduce the severity of coral bleaching and mortality (Bay \& Palumbi, 2015; Bellantuono, Granados-Cifuentes, Miller, Hoegh-Guldberg, \& Rodriguez-Lanetty, 2012; Palumbi, Barshis, Traylor-Knowles, \& Bay, 2014). Unfortunately, this natural protection mechanism could be lost under future climate-change scenarios (Ainsworth et al., 2016). One proposed solution for helping corals withstand future climate conditions is human-assisted evolution (Committee on Interventions to Increase the Resilience of Coral Reefs, Ocean Studies Board, Board on Life Sciences, Division on Earth and Life Studies, \& National Academies of Sciences, Engineering, and Medicine, 2019; Oppen et al., 2017). Whether it is selective breeding, managed relocation (assisted gene flow and migration), or genetic manipulations, the main setback is the fundamental lack of knowledge underlying mechanisms of coral-algal symbiosis maintenance and disruption. If we don't understand the mechanism of bleaching and natural acclimatization/adaptation of corals to heat stress, we can't responsibly define the attributes of resilience. Reversely, with a proper understanding of coral resilient traits and their trade-offs, current restoration projects could be scaled up to dramatically increase impact on coral reefs worldwide.

Despite global ecological relevance, surprisingly little is known about the cellular and molecular mechanisms of bleaching. In general, the observations point to two prevalent strategies involved in bleaching - apoptosis and autophagy/symbiophagy (Downs et al., 2009; Dunn, Schnitzler, \& Weis, 2007; Kvitt, Rosenfeld, \& Tchernov, 2016; Pernice et al., 2011; Tchernov et al., 2011). These two evolutionary conserved programmed cell death (PCD) pathways may occur independently but often simultaneously interplay or compensate for each other (Denton \& Kumar, 2019; Dunn et al., 2007). For example, key pro-survival genesBcl-2 (B-cell lymphoma 2) and BI-1 (Bax inhibitor 1) inhibit both apoptosis and autophagy, and pro-death genes BAX (Bcl2 Associated X) and BAK (Bcl2 Antagonist/Killer) activate them (Castillo et al., 2011; Karch et al., 2017; Xu et al., 2013).

Molecular analyses from previous bleaching experiments showed correlation of - among others - HSP70 (heat shock protein 70), and PCD genes Bcl-2, BI-1, BAK, and BAX expressions with bleaching, and proved the involvement of caspases - apoptotic proteases - in the process (Kvitt et al., 2016; Pernice et al., 2011; Tchernov et al., 2011). Transcriptomic studies in preconditioned/acclimatized corals focused mostly on the longer-term changes in gene expression profiles and found differences in the expressions of e.g. heat shock family proteins, genes involved in oxidative stress and various pleiotropic cell signaling and transcription factors such as TNFR (tumor necrosis factor receptor) or NFkB inhibitor (NFkBI)(Bay \& Palumbi, 2015; Bellantuono et al., 2012; Palumbi et al., 2014; Thomas et al., 2018). The early phase acute heat stress response and the role of PCD in preconditioning and acquired thermal resilience in corals is therefore not well understood. Moreover, the functional analyses of particular genes in the process are missing.

In our study, we used the heat susceptible stony coral Pocillopora acuta and we show that three-day exposure to sublethal temperature makes it more resilient to subsequent acute thermal stress via modulations in cell signaling. In preconditioned corals, the expression of pro-survival gene $p B c l$-2 increases relatively to prodeath genes $p B a k$ and $p B a x$ during early phase of the thermal stress. After pBcl-2 activity inhibition, preconditioned corals lose the acquired phenotype and bleach at the same rate as non-preconditioned corals, which determines the crucial role of pBcl-2 and programmed cell death in coral bleaching and acclimatization. Detailed analysis points to the involvement of autophagy/symbiophagy rather than apoptosis in the process. Corals exposed to natural oceanic summer temperatures show stress-induced gene expression profile similar to the experimentally preconditioned corals which suggests that during periods with high probability of extreme 
temperature events, corals can naturally increase their resilience through alterations in cell signaling.

\section{Results}

\section{Thermal preconditioning slows down the bleaching rate in $\mathrm{P}$. acuta}

We split colonies collected in Kaneohe Bay into three parts for preconditioned (PC), non-preconditioned (NPC) and control treatments. After 3 weeks of acclimatization to indoor tanks environment at winter ambient temperature $\left(26^{\circ} \mathrm{C}\right)$, PC part of each colony was exposed to the usual summer maximal temperature $\left(29^{\circ} \mathrm{C}\right)$ for 3 days and then rested at ambient $26^{\circ} \mathrm{C}$ for two weeks (Fig.1A). To assess thermal tolerance, we measured bleaching rate in each coral during a sudden heat stress $\left(32^{\circ} \mathrm{C}\right)$ using fluorescence confocal microscopy (Fig.1B, C). Each fragment of PC, NPC and control coral was live imaged at the beginning of the experiment and after 3 and 6 days. Red (algae) to green (host) signal ratio was calculated to quantify the density of Symbiodinium cells in coral tissue. Our results show that corals previously exposed to sublethal temperatures are more tolerant to acute heat stress and bleach at slower rate than non-preconditioned corals (two-way ANOVA, signal_ratio time ${ }^{*}$ conditioning, $\left.\mathrm{p}=0.000\right)($ Fig. $1 \mathrm{C})$. To eliminate that the shift in red to green signal ratio is caused by increased level of pGFP in coral tissue as response to heat stress, we analyzed $p G F P$ expression via qPCR and observed no differences (data not shown).

Previous experiments have already shown the ability of corals to increase their tolerance to heat stress after exposure to sublethal temperatures (Ainsworth et al., 2016; Bay \& Palumbi, 2015; Bellantuono et al., 2012). It seems that the length of sublethal temperature exposure along with the length and temperature of the resting period are more important for the acquired thermal resilience than the preconditioning temperature. Our experiment is unique because it combines relatively short preconditioning period with relatively long resting time.

\section{pHSP70 expression increases after preconditioning}

To unveil the molecular mechanisms underlying acquired higher thermal resilience in preconditioned corals, we first analyzed the early hyperthermal stress response of PC and NPC corals by RT-qPCR. We expected lively cell signaling reflected in rapid changes in gene expression to occur in corals during the first $24 \mathrm{~h}$ of acute heat stress. To increase the chance of capturing these changes, we sampled PC and NPC corals $(\mathrm{n}=10$ per conditioning) exposed to $32^{\circ} \mathrm{C}$ at $0,1,3,6,12,24,48$, and 72 hours. To exclude the influence of natural circadian gene expression oscillation, control samples (NPC corals at ambient temperature) were sampled as well. We expressed gene expression level relatively to control at time 0 . Considering the qPCR calculation method and the fact that gene expression changes are very dynamic and can happen in only a very short time window with no regards to previous or future levels, we analyzed the results independently for every timepoint using one-way ANOVA.

Heat shock proteins (HSP) are considered first-line stress responders, protecting other proteins from misassembling during extreme conditions. In our system, the expression of $p H S P^{r} 0$ was very heterogeneous and colony-specific (Fig. 2A). We observed a small increase in $H S P 70$ gene expression in NPC corals compared to control after heat stress. This result supports previous experiments that showed high variability in basal expression of HSP proteins depending on colony depth (Poli, Fabbri, Goffredo, Airi, \& Franzellitti, 2017). Corals living in shallow waters (up to $3 \mathrm{~m}$ ) have high basal $p H S P$ 70 expression and do not increase it significantly during heat shock, suggesting that their molecular guard mechanisms stay on alert all the time. Pocillopora corals for our experiment were collected from shallow waters (1-4m), which potentially clarifies why we did not detect changes in $\mathrm{pHSP} 70$ expression in NPC corals. Nevertheless, after preconditioning, $\mathrm{p} H S P 70$ gene expression increased at two timepoints $-3 \mathrm{~h}(\mathrm{p}=0.053)$ and $24 \mathrm{~h}(\mathrm{p}=0.070)$ compared to NPC corals. The function of HSP in preconditioning and acclimatization remains disputed. Palumbi et al. observed alterations in HSP family gene expression after acclimatization (Palumbi et al., 2014), but others detected only limited (Bay \& Palumbi, 2015) or no (Bellantuono et al., 2012) differences. Considering the 
dynamics of HSP70 expression, detection of its alterations is largely dependent on the experimental design and different observations might be attributed to different sampling times.

Transcription of HSP is regulated by HSF1 transcription factor (Pirkkala, Nykänen, \& Sistonen, 2001). In our experiment, pHSF1 basal expression level was higher in non-stressed PC corals $(\mathrm{p}=0.000)$ but after the beginning of heat stress, the levels of PC and NPC corals aligned until day 3 when we observed significant decrease of HSF1 expression in NPC corals $(\mathrm{p}=0.001)$ (Figure S1). The expression of pHSF1 does not correlate with the expression of HSP70, which is not much surprising since changes in gene expression may be caused by many other factors such as transcription factor localization, promoter accessibility etc.

\section{Thermal preconditioning shifts cell signaling in favor of pro-life genes pBcl-2 and pBI-1}

Expression of pro-survival genes $\mathrm{p} B I-1$ and $\mathrm{p} B c l-2$ and pro-death genes $\mathrm{p} B A K$ and $\mathrm{p} B A X$ increased during first six hours of the stress (Fig. 2A). After preconditioning, the increase of $\mathrm{p} B I-1, p B c l-2$ and $\mathrm{p} B A X$ expression was even more pronounced $\left(\mathrm{p}_{(\mathrm{BI}-1,3 \mathrm{~h})}=0.006, \mathrm{p}_{(\mathrm{Bcl}-2,0 \mathrm{~h})}=0.076, \mathrm{p}_{(\mathrm{Bcl}-2,3 \mathrm{~h})}=0.002, \mathrm{p}_{(\mathrm{BAX}, 1 \mathrm{~h})}\right.$ $\left.=0.027, \mathrm{p}_{(\mathrm{BAX}, 3 \mathrm{~h})}=0.014\right)$, but the expression of pro-death $B A K$ gene in PC corals dropped to control levels at 6 hours, differing from the NPC corals $(\mathrm{p}=0.084)$. Upon proper signaling, BAK and BAX heterodimerize and permeabilize mitochondrial membrane, releasing cytochrome $\mathrm{c}$ and considerably progressing towards cell death (Galluzzi et al., 2018; Karch et al., 2017). Bcl-2 can antagonize this process via direct protein-protein interaction with both BAK and BAX. BI-1 acts as an apoptosis inhibitor but the exact mechanism is still not fully understood. PCD signaling consists of a complex protein networking where single gene expression profile does not reflect the entirety of the process. For this reason, we calculated the expression ratio of prosurvival vs. pro-death genes to better express the prevalent signalization in the cell. After preconditioning, the $\mathrm{pBcl} / \mathrm{pBAK}, \mathrm{pBcl} / \mathrm{pBAX}$, and $\mathrm{pBI} / \mathrm{pBAX}$ ratios shift towards the pro-survival partner during the early heat-stress response (Fig. 2B). $\mathrm{p} B I-1$ expression level is higher than the $\mathrm{p} B A X$ expression level in $\mathrm{PC}$ vs. NPC corals at the first hour after stress $(\mathrm{p}=0.058) . \mathrm{p} B c l-2$ is expressed considerably more than the $\mathrm{p} B A K$ gene at 3 hours $(\mathrm{p}=0.002)$, while compared to $\mathrm{p} B A X$, it's the basal expression of $\mathrm{p} B c l-2$ in non-stressed $\mathrm{PC}$ corals and the expression around $1 \mathrm{~h}$ of the stress that is higher $\left(\mathrm{p}_{(0 \mathrm{~h})}=0.005, \mathrm{p}_{(\mathrm{h})}=0.084\right)$. All these results suggest that during thermal preconditioning, coral PCD signaling is manipulated to favor the pro-survival genes.

\section{Stress response in naturally acclimatized corals correspond to experimentally preconditioned corals}

In vitro experiments may not always reflect the natural behavior of the organism. To analyze the stress response of naturally acclimatized corals, we collected six Pocillopora acuta colonies living in the outdoor flow-through tanks (WT) at the beginning of September 2019, when water temperatures peaked $29^{\circ} \mathrm{C}$ in Kaneohe bay (Fig. S2). We let them acclimate to winter ambient $26^{\circ} \mathrm{C}$ to simulate our preconditioning experiment and then exposed them to acute heat stress $\left(32^{\circ} \mathrm{C}\right)$. The correlation of gene expression between WT and PC corals during acute heat stress was surprisingly high (Fig 3, S2) showing that corals react to peaking temperatures in a similar way as to natural temperature profile. It also suggests that during summer, when the risk of extreme weather causing warming events and mass coral bleaching is the highest, corals naturally acclimatize to warm temperatures through modulations in the PCD pathways, which increase their survival chances by slowing down the bleaching rate.

\section{pBcl-2 inhibition leads to the loss of higher thermal resilience in preconditioned corals}

Previous experiments focused on the correlation of gene expression differences with preconditioning or acclimatization (Bay \& Palumbi, 2015; Bellantuono et al., 2012; Palumbi et al., 2014), but deeper insight into mechanisms of such processes is missing. Here, we investigated whether higher pro-survival gene expression prevents coral from bleaching, by inhibiting the effect of pBcl-2 in PC corals. If the acquired higher thermotolerance is caused by the pro-survival shift in PCD pathway, inhibition of pBcl-2 function should result in the loss of the beneficial phenotype. Venetoclax is a BH3 mimetic small molecule that binds to Bcl-2 protein binding domain, blocking its molecular function (Souers et al., 2013). Six PC and NPC corals were exposed to acute heat stress $\left(32^{\circ} \mathrm{C}\right)$ and simultaneously treated with $1 \mu \mathrm{M}$ venetoclax or with DMSO (for control). 
Fragments were also treated with venetoclax at ambient temperature to exclude the impact of venetoclax itself to coral bleaching. The bleaching ratio was assessed via confocal microscopy at the beginning of the experiment and after 5 days of heat stress. Control samples showed no effect of venetoclax to bleaching rate at ambient temperature, but we observed significant differences in the phenotype of corals treated and not treated with venetoclax under heat stress (Fig. 4, S3). After the application of venetoclax, the beneficial phenotype was completely lost, and PC corals bleached at the same rate as NPC corals (multi-way ANOVA microscopy_signal ${ }^{\sim}$ time ${ }^{*}$ conditioning $*$ treatment; $\$$ conditioning $:$ treatment $-\mathrm{p}_{(\mathrm{ven}-)}=0.000, \mathrm{p}_{(\mathrm{ven}+)}=$ 0.464). Our data show for the first time the direct functional involvement of PCD genes in coral thermal tolerance and preconditioning.

\section{AMPK gene expression and caspase-3 activity points to autophagy/symbiophagy as the main bleaching pathway in $\mathrm{P}$. acuta}

Bcl-2 gene is involved in both apoptosis and autophagy pathways (Xu et al., 2013). In order to distinguish between these two programmed cell death pathways, we analyzed activity of caspase-3, one the key apoptotic effector proteases. We performed caspase-3 activity test in thermally stressed PC and NPC corals at times 0,3 days and 5 days, and in PC and NPC corals treated with venetoclax to exclude the switch in PCD pathways upon treatment. Both PC and NPC corals showed slightly increased caspase-3 activity under thermal stress, but significantly lower compared to colchicine-induced apoptosis (Fig. 5A).

Moreover, we analyzed expression profile of $p A M P K$ (adenosine monophosphate-activated protein kinase), a major signal inducer of autophagy pathway, triggered by ROS(Villanueva-Paz et al., 2016).pAMPK was significantly upregulated at 6 hours post-stress in NPC vs PC $(\mathrm{p}=0.010)$ and after 24 hours we observed a gradual increase in AMPK levels in NPC, peaking at 72 hours with almost three times higher mean expression than in $\mathrm{PC}$ corals $(\mathrm{p}=0.077)$ (Fig. 5B).

The expression of pNFkB in PC and NPC corals supports the involvement of autophagy/symbiophagy in P. acuta bleaching

pBcl-2 and other involved proteins are the effectors in the PCD signaling, not the triggers. That's why we analyzed the expression rate of $\mathrm{NFkB}$, a pleiotropic transcription factor (TF) involved in many crucial cellular processes. In response to various stressors, $\mathrm{NFkB}$ is translocated to nucleus where it usually triggers transcription of pro-survival genes such as Bcl-2 (Luo, Kamata, \& Karin, 2005). Increased expression levels of $N F k B$ as a result of hyperthermal shock have been observed in coral Acropora palmata (DeSalvo, Sunagawa, Voolstra, \& Medina, 2010). Moreover, Bellantuono et al. observed increased levels of NFkB inhibitor (NFKBI ) in thermally PC corals (Bellantuono et al., 2012). Our results also show increasedNFKBI expression levels in PC vs NPC corals $\left(\mathrm{p}_{(0 \mathrm{~h})}=0.003, \mathrm{p}_{(1 \mathrm{~h})}=0.013\right)$ (Fig. 5B). It suggests the role of NFkB in corals is to promote, not to prevent cell death. It is known that NFkB is involved in innate immune system across species (Gilmore \& Wolenski, 2012). It promotes organismal immune reaction to get rid of the pathogen while it enhances the capability of the host cells to survive. One of the algal-coral symbiosis theories suggests that coral symbiont forms an intracellular organelle called the symbiosome, which is a late endosome in the state of arrested phagocytosis (Davy, Allemand, \& Weis, 2012). Under stress conditions, the host innate immune response is reactivated leading to a specific type of autophagy called symbiophagy. Autophagy and NFkB pathway share common upstream signals and can control each other (Trocoli \& Djavaheri-Mergny, 2011). During signaling, NFkB represses autophagy through activation of mTOR, but under specific conditions such as presence of reactive oxygen species (ROS) or after heat shock, NFkB directly activates autophagy (Trocoli \& Djavaheri-Mergny, 2011). It has been well documented that symbionts release increased ROS during heat stress due to overexcitation of their photosynthetic systems, and symbiophagy is one of the main observed mechanisms of algal loss in hyperthermia (Downs et al., 2009; Dunn et al., 2007). NFkB has the potential to link these two processes. 


\section{Discussion}

Our data show that heat-susceptible stony coral Pocillopora acutacan become more heat stress tolerant after previous exposure to sublethal temperatures through modulations in cell signaling. In preconditioned corals, the expression of pro-survival gene $\mathrm{pBcl}-2$ increases relatively to pro-death genes pBak and pBax during acute thermal stress. After pBcl-2 activity inhibition, this beneficial phenotype is lost and preconditioned corals bleach at the same rate as non-preconditioned ones. It implies direct involvement of programmed cell death pathways in coral bleaching, but due to the complexity and interconnection of these pathways, it is difficult to identify it precisely (Castillo et al., 2011; Denton \& Kumar, 2019; Dunn et al., 2007; Karch et al., 2017; Xu et al., 2013). Yet, our results indicate that autophagy, not apoptosis, underlies bleaching in P. acutaduring acute heat stress. Corals activate autophagy as a part of their immune system to eliminate intracellular bacteria (Fuess, Pinzón C, Weil, Grinshpon, \& Mydlarz, 2017). From this point of view, autophagy is mostly regarded as a cell rescue pathway that allows organism to get rid of pathogens and reuse autophaged cell components as a new energetic source. In the light of existing literature and our results, we hypothesize that upon acute heat stress, coral induces symbiophagy through AMPK signaling to eliminate algae producing high levels of ROS and other toxins. At the same time, it recycles algal cellular components to meet its energetic demands. This strategy of feeding on its symbionts would solve two problems at once and would allow coral to survive for prolongated time even without its symbiont. Our hypothesis is partially backed up by the recent findings showing that corals in Kaneohe Bay did not increase heterotrophic nutrition during a 2014 mass bleaching event but significantly lowered their biomass, suggesting that they could have digest symbionts and their own tissues to survive stress conditions (Wall, Ritson-Williams, Popp, \& Gates, 2019). After preconditioning, cell signalization changes, and corals slow down the bleaching rate thus extending the period of autotrophic feeding and decreasing the chances of death by starvation.

Analysis of heat stress-induced gene expression in corals naturally acclimatized to summer temperatures showed striking correlation to gene expression in experimentally preconditioned corals but not in nonpreconditioned corals acclimatized to winter temperature. It suggests that such preconditioning is a natural phenomenon that serves to temporarily increase heat resilience in corals during summer, when the risk of extreme weather event increases, but is lost towards winter months.

What exactly triggers this process and what the downstream consequences of keeping the symbionts throughout hostile thermal conditions are needs to be addressed and elucidated in future experiments.

We add new pieces to the understanding of coral plasticity in responding to heat stress and their capability to acclimatize to changing conditions via preconditioning. Nevertheless, some future climate scenarios predict changes so severe that this natural mechanism could be inefficient (Ainsworth et al., 2016). Thus, it is important to search for other ways to protect coral reefs. Human-assisted evolution approach supported by technology development (e.g. CRISPR/Cas mediated genome editing made possible in corals (Cleves, Strader, Bay, Pringle, \& Matz, 2018)) offers various solutions for scientists and coral restoration practitioners (Committee on Interventions to Increase the Resilience of Coral Reefs et al., 2019; Oppen et al., 2017), but without proper understanding of resilient traits and their cellular and molecular background, they have only a limited chance to succeed.

\section{Methods and Material}

\section{Coral growth, preconditioning and treatments}

Colonies of P. acuta were collected in Kaneohe Bay, Hawaii in depths ranging between 1 to $4 \mathrm{~m}$ and placed in temperature and light controlled flow-through indoor tanks for acclimation. The ambient temperature was set to 26degC. Light controlling system (Radion XR30w G3 Pro LED Light, EcoTech Marine) template for shallow reef at $2 \mathrm{~m}$ depth with maximum light intensity of $35 \%$ was set to imitate natural reef light conditions. After one-month acclimation, eight coral colonies were cut to three parts for preconditioned 
(PC), non-preconditioned (NPC) and control treatments. Control and NCP corals were left at ambient temperature while PC corals were exposed to sublethal $29 \mathrm{degC}$ temperature for 72 hours and then returned to ambient $26 \mathrm{deg} \mathrm{C}(0.5 \mathrm{deg} \mathrm{C}$ per 4 hours decrease rate) to rest. After two days, all corals were sub-fragmented, and fragments were put in respective tanks for ambient or hyperthermal treatment. Twelve days later two weeks after the preconditioning - PC and NPC coral fragments were exposed to an acute thermal stress when temperature ramped from $26 \mathrm{degC}$ to $32 \mathrm{degC}$ in $~ 2$ hours. At time points $1 \mathrm{~h}, 3 \mathrm{~h}, 6 \mathrm{~h}, 12 \mathrm{~h}, 24 \mathrm{~h}$, and $72 \mathrm{~h}$, one fragment of each treatment (PC and NPC at $32 \mathrm{degC}$ and control at $26 \mathrm{degC}$ ) was cut to $0.5-2 \mathrm{~cm}$ long pieces, aliquoted, washed with filtered sea water (FSW) and stored dry at -80degC.

For Bcl-2 inhibition, PC and NPC fragments were treated with $1 \mu \mathrm{M}$ venetoclax for the first 6 hours of the acute heat stress and then placed to venetoclax-free sea water $\left(32^{\circ} \mathrm{C}\right)$ for the rest of the experiment. Fragments were microscoped prior to the treatment and then at day 5 of the heat stress. The total of 7 colonies were used for the venetoclax experiment but for statistical purposes, the data of only 5 colonies were used because NPC fragments and PC fragments with venetoclax of two colonies did not survive to day 5 of heat stress.

To compare heat stress response of experimentally preconditioned corals with naturally acclimatized corals, we collected 6 colonies (WT) from our outdoor flow-through tanks at the beginning of September 2018, when water temperatures peaked $29^{\circ} \mathrm{C}$ in Kaneohe bay. We let them acclimate to winter ambient $26^{\circ} \mathrm{C}$ to simulate our preconditioning experiment, sub-fragmented them as described above, and then exposed them to acute heat stress $\left(32^{\circ} \mathrm{C}\right)$. We sampled and stored them in the same way as described above.

\section{Bleaching rate assessment}

Fragments of PC and NPC corals were live imaged with Zeiss LSM-710 confocal microscope at the beginning of the experiment and at days 3 and 5 of the heat stress to assess the rate of symbiont loss, or only at day 5 for venetoclax experiment. EC Plan-Neofluar $2.5 \mathrm{X} / 0.075$ objective was used for the imaging resulting in total magnification 25X. Images were acquired with Zen Imaging Software (Black edition) by Zeiss. Host cell fluorescence was excited with the $405 \mathrm{~nm}$ laser and collected in emission range 454-621nm with master gain set at 650, digital gain 1.0, laser power $28 \%$ and pinhole 35.5. Symbiodinium fluorescence was excited with the $405 \mathrm{~nm}$ laser and collected in emission range $655-718 \mathrm{~nm}$ with master gain set at 575 , digital gain 1.0, laser power $28 \%$ and pinhole 35.5. Fragments were kept in saltwater of respective temperature $\left(26^{\circ} \mathrm{C}\right.$ and $32^{\circ} \mathrm{C}$ ) during all the microscoping. Three snap images of each fragment were taken using two fragments per treatment (control, ven + at $26^{\circ} \mathrm{C}$, ven- at $32^{\circ} \mathrm{C}$, and ven + at $32^{\circ} \mathrm{C}$ ) per colony, with the total of 6 colonies. Images were analyzed with ZEN Imaging Software. The ratio of green to red signal intensity (in fluorescence units) was analyzed in ten circular areas along the coral tissue (avoiding mouth and tentacles area) in each image. Two-way ANOVA (microscopy_signal time * conditioning) with Tukey's post hoc test was used to compare bleaching rate between PC and NPC corals. Multiway ANOVA analysis with Tukey's post hoc test (microscopy_signal time * conditioning * treatment) was used to test the similarity of bleaching rate between PC and NPC corals treated with venetoclax or with DMSO. Controls (corals treated with venetoclax or with DMSO at ambient temperature) were analyzed as an independent experiment.

\section{Gene expression analysis}

Total RNA was extracted from dry frozen coral samples (size $\sim 0.5-1.5 \mathrm{~cm}$ ) with RiboZol ${ }^{\mathrm{TM}}$ RNA Extraction Reagent (VWR Life Science) followed by DNase treatment (DNaseI, Zymo Research) and phenol-chloroform extraction. We performed the DNase treatment in $50 \mu \mathrm{l}$ with $1 \mathrm{U}$ of DNase I at $37^{\circ} \mathrm{C}$ for 15 min and to increase the efficiency - with additional $1 \mathrm{U}$ for $25 \mathrm{~min}$. $1 \mu \mathrm{g}$ of RNA was reversely transcribed with High-Capacity cDNA reverse transcription kit (ThermoFisher Scientific) with RiboLock RNase inhibitor (ThermoFisher Scientific). Reverse transcription quantitative PCR (RT-qPCR) reactions were ran in $12 \mu l$ with PowerUp ${ }^{\mathrm{TM}} \mathrm{SYBR}^{\mathrm{TM}}$ Green Master Mix (Applied Biosystems) for 40 cycles. Four gene expression profiles - pActin, $p E F-1 a$ (elongation factor 1), pCalm (calmodulin) and $p A H C$ (AdenosylHomoCysteinase) - were compared in five different treatments and pEF-1a showed the highest expression stability upon heat stress and thus chosen as the reference gene. All primer sequences are listed in Table S1. 
Expression of target genes was calculated relatively to the control treatment at time 0 with $\Delta \Delta \mathrm{Ct}$ method.

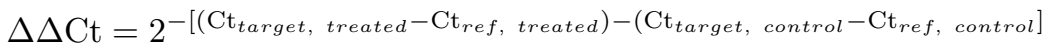

$\Delta \Delta \mathrm{Ct}$ calculation method returns gene expression relative to control coral at time 0 without reflecting RNA levels at other timepoints. Moreover, we analyzed mostly genes involved in cell signaling whose gene expression can change very promptly after the signaling occurs and the change can last for only a very short period of time. Thus, the gene expression levels are similar between treatments for most of the time, with only a few differing timepoints. For these reasons, we excluded time as a variable from our statistical analysis and analyzed expression rates individually for each timepoint using One-way ANOVA with Tukey's post hoc test. We sampled corals at different times only to increase the chance of capturing gene expression changes, not to compare the entire gene expression patterns between different treatments. Including time as a variable decreases the probability that a gene expression difference will be detected.

To compare gene expression profiles between experimentally preconditioned (PC) and naturally acclimatized (WT) corals during heat stress, linear regression model with Pearson correlation was calculated for mean single gene expression and mean gene expression ratios between PC and WT.

\section{Caspase activity assay}

Coral fragments (size $\sim 0.5-1.5 \mathrm{~cm}$ ) were dry-frozen and kept at $-80^{\circ} \mathrm{C}$. Prior the assay, host and algal cells were separated as follows. Frozen fragments were placed on ice in $1.5 \mathrm{ml}$ tubes with $250 \mathrm{\mu l}$ of ice cold EB buffer (100mM Tris, 20mM EDTA, pH 8.0). Glass beads (Sigma Aldrich, G1152) were added to the corals, each fragment was vortexed in short pulses for 20 s and then placed immediately back on ice. Samples were centrifugated at $500 \mathrm{~g}$ for $5 \mathrm{~min}$ at $4^{\circ} \mathrm{C}$. $50 \mu \mathrm{l}$ of host cell containing supernatant was transferred to a new tube and lysed with Cell Lysis Buffer according to instructions in EnzChek ${ }^{\text {TM }}$ Caspase-3 Assay Kit \#1, ZDEVD-AMC substrate (ThermoFisher Scientific). Protein concentration was measured with Qubit Protein Assay Kit (Life Technologies). 50ug of protein in volume of $50 \mu \mathrm{l}$ or lower was used to measure caspase 3 activity following the kit instructions. Fluorescence was measured with SpectraMax2 (Molecular devices) using SoftMax Pro v4.8 software. Caspase activity was analyzed in 6 colonies for heat stress experiment, and in 4 colonies for the venetoclax and colchicine experiments.

\section{Acknowledgments}

We thank to the members and interns of the Gates Coral Lab, especially to Vojtěch Prokůpek, for assistance with fieldwork, coral fragmenting and sampling, as well as to Nicole Cernohorsky, Ariana S. Huffmyer and Crawford Drury for their valuable comments on the statistical analysis and RStudio programming. We also thank Crawford Drury for his comments on the manuscript. The research reported in this publication was supported by the Paul G. Allen Foundation.

\section{Author contributions}

E.M. and R.D.G conceived and coordinated the project, E.M. and F.C.C. collected samples from the wild, ran the preconditioning experiment, and assessed the bleaching rate in corals. E.M extracted RNA and analyzed gene expression, performed Caspase-3 activity experiments and statistically analyzed the data. E.M. wrote the manuscript. E.M. and F.C.C. read and approved the manuscript. 


\section{Data Accessibility Statement}

The data that supports the findings of this study are available in the supplementary material of this article

\section{References}

Ainsworth, T. D., Heron, S. F., Ortiz, J. C., Mumby, P. J., Grech, A., Ogawa, D., .. Leggat, W. (2016). Climate change disables coral bleaching protection on the Great Barrier Reef. Science ,352 (6283), 338-342. doi: $10.1126 /$ science.aac7125

Bay, R. A., \& Palumbi, S. R. (2015). Rapid Acclimation Ability Mediated by Transcriptome Changes in Reef-Building Corals. Genome Biology and Evolution , 7 (6), 1602-1612. doi: 10.1093/gbe/evv085

Bellantuono, A. J., Granados-Cifuentes, C., Miller, D. J., Hoegh-Guldberg, O., \& Rodriguez-Lanetty, M. (2012). Coral Thermal Tolerance: Tuning Gene Expression to Resist Thermal Stress. PLoS ONE , 7 (11), e50685. doi: 10.1371/journal.pone.0050685

Castillo, K., Rojas-Rivera, D., Lisbona, F., Caballero, B., Nassif, M., Court, F. A., ... Hetz, C. (2011). BAX inhibitor-1 regulates autophagy by controlling the IRE1 $\alpha$ branch of the unfolded protein response. The EMBO Journal , 30 (21), 4465-4478. doi: 10.1038/emboj.2011.318

Cleves, P. A., Strader, M. E., Bay, L. K., Pringle, J. R., \& Matz, M. V. (2018). CRISPR/Cas9-mediated genome editing in a reef-building coral.Proceedings of the National Academy of Sciences , 115 (20), 52355240. doi: $10.1073 /$ pnas. 1722151115

Committee on Interventions to Increase the Resilience of Coral Reefs, Ocean Studies Board, Board on Life Sciences, Division on Earth and Life Studies, \& National Academies of Sciences, Engineering, and Medicine. (2019). A Research Review of Interventions to Increase the Persistence and Resilience of Coral Reefs . doi: $10.17226 / 25279$

Couch, C. S., Burns, J. H. R., Liu, G., Steward, K., Gutlay, T. N., Kenyon, J., .. Kosaki, R. K. (2017). Mass coral bleaching due to unprecedented marine heatwave in Papahānaumokuākea Marine National Monument (Northwestern Hawaiian Islands). PLoS ONE , 12 (9). doi: 10.1371/journal.pone.0185121

Davy, S. K., Allemand, D., \& Weis, V. M. (2012). Cell Biology of Cnidarian-Dinoflagellate Symbiosis. Microbiology and Molecular Biology Reviews , 76 (2), 229-261. doi: 10.1128/MMBR.05014-11

Denton, D., \& Kumar, S. (2019). Autophagy-dependent cell death.Cell Death \&3 Differentiation , 26 (4), 605-616. doi: 10.1038/s41418-018-0252-y

DeSalvo, M., Sunagawa, S., Voolstra, C., \& Medina, M. (2010). Transcriptomic responses to heat stress and bleaching in the elkhorn coral Acropora palmata. Marine Ecology Progress Series ,402 , 97-113. doi: $10.3354 /$ meps08372

Downs, C. A., Kramarsky-Winter, E., Martinez, J., Kushmaro, A., Woodley, C. M., Loya, Y., \& Ostrander, G. K. (2009). Symbiophagy as a cellular mechanism for coral bleaching. Autophagy , 5 (2), 211-216.

Dunn, S. R., Schnitzler, C. E., \& Weis, V. M. (2007). Apoptosis and autophagy as mechanisms of dinoflagellate symbiont release during cnidarian bleaching: every which way you lose. Proceedings of the Royal Society B: Biological Sciences , 274 (1629), 3079-3085. doi: 10.1098/rspb.2007.0711

Frieler, K., Meinshausen, M., Golly, A., Mengel, M., Lebek, K., Donner, S. D., \& Hoegh-Guldberg, O. (2013). Limiting global warming to $2{ }^{\circ} \mathrm{C}$ is unlikely to save most coral reefs. Nature Climate Change, 3 (2), 165-170. doi: 10.1038/nclimate1674 
Fuess, L. E., Pinzón C, J. H., Weil, E., Grinshpon, R. D., \& Mydlarz, L. D. (2017). Life or death: diseasetolerant coral species activate autophagy following immune challenge. Proceedings of the Royal Society B: Biological Sciences , 284 (1856), 20170771. doi: 10.1098/rspb.2017.0771

Galluzzi, L., Vitale, I., Aaronson, S. A., Abrams, J. M., Adam, D., Agostinis, P., .. Kroemer, G. (2018). Molecular mechanisms of cell death: recommendations of the Nomenclature Committee on Cell Death 2018. Cell Death \&3 Differentiation , 25 (3), 486-541. doi: 10.1038/s41418-017-0012-4

Gilmore, T. D., \& Wolenski, F. S. (2012). NF- $x$ B: where did it come from and why?: Evolution of NF- $x$ B. Immunological Reviews ,246 (1), 14-35. doi: 10.1111/j.1600-065X.2012.01096.x

Hoegh-Guldberg, O., Beal, D., Chaudhry, T., Elhaj, H., Abdullat, A., Etessy, P., \& Smits, M. (2015). Reviving the Ocean Economy: the case for action. WWF International, Gland, Switzerland., Geneva.

Karch, J., Schips, T. G., Maliken, B. D., Brody, M. J., Sargent, M. A., Kanisicak, O., \& Molkentin, J. D. (2017). Autophagic cell death is dependent on lysosomal membrane permeability through Bax and Bak. ELife ,6 . doi: 10.7554/eLife.30543

Kvitt, H., Rosenfeld, H., \& Tchernov, D. (2016). The regulation of thermal stress induced apoptosis in corals reveals high similarities in gene expression and function to higher animals. Scientific Reports , 6 (1). doi: 10.1038/srep30359

Luo, J.-L., Kamata, H., \& Karin, M. (2005). IKK/NF- $x$ B signaling: balancing life and death - a new approach to cancer therapy.Journal of Clinical Investigation , 115 (10), 2625-2632. doi: 10.1172/JCI26322

Oppen, M. J. H. van, Gates, R. D., Blackall, L. L., Cantin, N., Chakravarti, L. J., Chan, W. Y., .. P Putnam, H. M. (2017). Shifting paradigms in restoration of the world's coral reefs. Global Change Biology , 23 (9), 3437-3448. doi: 10.1111/gcb.13647

Palumbi, S. R., Barshis, D. J., Traylor-Knowles, N., \& Bay, R. A. (2014). Mechanisms of reef coral resistance to future climate change.Science , 344 (6186), 895-898. doi: 10.1126/science.1251336

Pernice, M., Dunn, S. R., Miard, T., Dufour, S., Dove, S., \& Hoegh-Guldberg, O. (2011). Regulation of Apoptotic Mediators Reveals Dynamic Responses to Thermal Stress in the Reef Building Coral Acropora millepora. PLoS ONE , 6 (1), e16095. doi: 10.1371/journal.pone.0016095

Pirkkala, L., Nykänen, P., \& Sistonen, L. (2001). Roles of the heat shock transcription factors in regulation of the heat shock response and beyond. FASEB Journal: Official Publication of the Federation of American Societies for Experimental Biology , 15 (7), 1118-1131. doi: 10.1096/fj00-0294rev

Poli, D., Fabbri, E., Goffredo, S., Airi, V., \& Franzellitti, S. (2017). Physiological plasticity related to zonation affects hsp70 expression in the reef-building coral Pocillopora verrucosa. PLOS ONE, 12 (2), e0171456. doi: 10.1371/journal.pone.0171456

Souers, A. J., Leverson, J. D., Boghaert, E. R., Ackler, S. L., Catron, N. D., Chen, J., .. Elmore, S. W. (2013). ABT-199, a potent and selective BCL-2 inhibitor, achieves antitumor activity while sparing platelets. Nature Medicine , 19 (2), 202-208. doi: 10.1038/nm.3048

Tchernov, D., Kvitt, H., Haramaty, L., Bibby, T. S., Gorbunov, M. Y., Rosenfeld, H., \& Falkowski, P. G. (2011). Apoptosis and the selective survival of host animals following thermal bleaching in zooxanthellate corals. Proceedings of the National Academy of Sciences ,108 (24), 9905-9909. doi: 10.1073/pnas.1106924108

Thomas, L., Rose, N. H., Bay, R. A., López, E. H., Morikawa, M. K., Ruiz-Jones, L., \& Palumbi, S. R. (2018). Mechanisms of Thermal Tolerance in Reef-Building Corals across a Fine-Grained Environmental Mosaic: Lessons from Ofu, American Samoa. Frontiers in Marine Science , 4 . doi: 10.3389/fmars.2017.00434

Trocoli, A., \& Djavaheri-Mergny, M. (2011). The complex interplay between autophagy and NF- $x$ B signaling pathways in cancer cells.American Journal of Cancer Research , 1 (5), 629-649. 
Vercelloni, J., Clifford, S., Caley, M. J., Pearse, A. R., Brown, R., James, A., .. Peterson, E. E. (2018). Using virtual reality to estimate aesthetic values of coral reefs. Royal Society Open Science , 5 (4). doi: $10.1098 /$ rsos. 172226

Villanueva-Paz, M., Cotán, D., Garrido-Maraver, J., Oropesa-Ávila, M., de la Mata, M., Delgado-Pavón, A., ... Sánchez-Alcázar, J. A. (2016). AMPK Regulation of Cell Growth, Apoptosis, Autophagy, and Bioenergetics. In M. D. Cordero \& B. Viollet (Eds.),AMP-activated Protein Kinase (Vol. 107, pp. 45-71). doi: 10.1007/978-3-319-43589-3_3

Wall, C. B., Ritson-Williams, R., Popp, B. N., \& Gates, R. D. (2019). Spatial variation in the biochemical and isotopic composition of corals during bleaching and recovery. Limnology and Oceanography ,64 (5), 2011-2028. doi: 10.1002/lno.11166

Xu, H.-D., Wu, D., Gu, J.-H., Ge, J.-B., Wu, J.-C., Han, R., .. Qin, Z.-H. (2013). The Pro-Survival Role of Autophagy Depends on Bcl-2 Under Nutrition Stress Conditions. PLOS ONE , 8 (5), e63232. doi: 10.1371/journal.pone.0063232

\section{Figures}

Figure 1
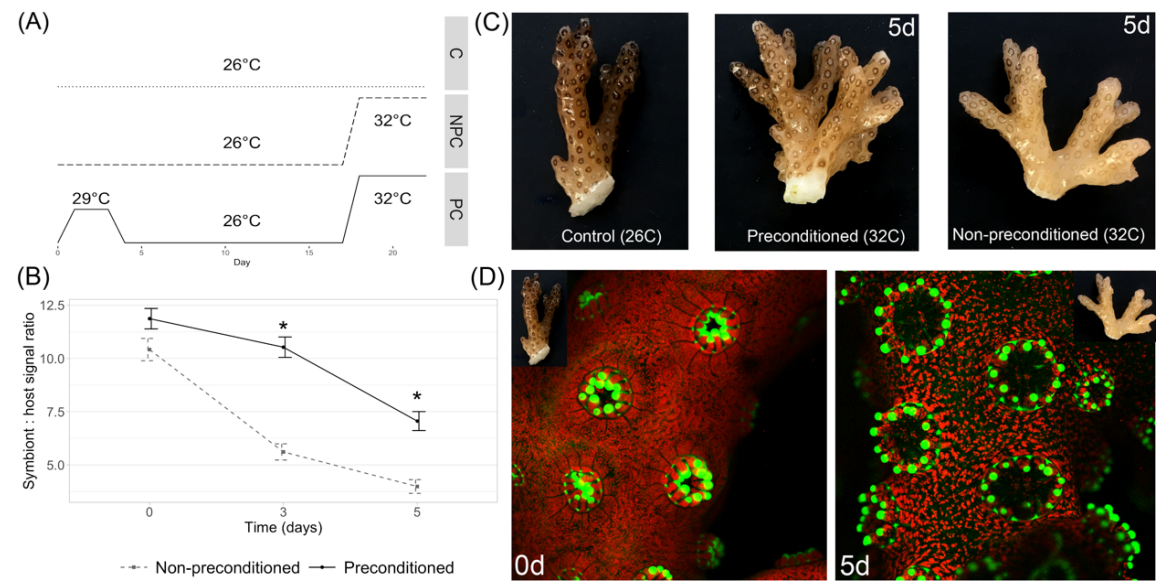

Figure 1 Corals exposed to sublethal temperature $\left(29^{\circ} \mathrm{C}\right)$ for 3 days become more resilient to following acute heat stress $\left(32^{\circ} \mathrm{C}\right)$. A) Graphical depiction of preconditioning experiment layout. $\mathrm{C}$ - control corals, NPC - non-preconditioned corals, PC - preconditioned corals. B) Bleaching rate of PC and NPC corals upon acute heat stress expressed as symbiont to host cell signal ratio based on confocal fluorescence microscopy. Graph shows that PC corals are more resilient to thermal stress and bleach with significantly slower pace than NPC corals. NPC corals are depicted with grey dashed line, PC with black solid line. Graph shows mean values with standard error bars. Two-way ANOVA (microscopy_signal time * conditioning, $\mathrm{p}=0.000$ ) was used to test the influence of conditioning to the bleaching rate. ${ }^{*}$ marks significantly different values in Tukey's post hoc test ( $\mathrm{p}$ [?] 0.001), $\mathrm{n}=6$. C) PC and NPC coral fragments after 5-day long heat stress exposure compared to control coral. D) Confocal fluorescence microscopy image of control (left) and bleached (right) coral. Host cells (GFP) are depicted in green, algal cells (chlorophyll) in red.

Figure 2 


\section{(A)}

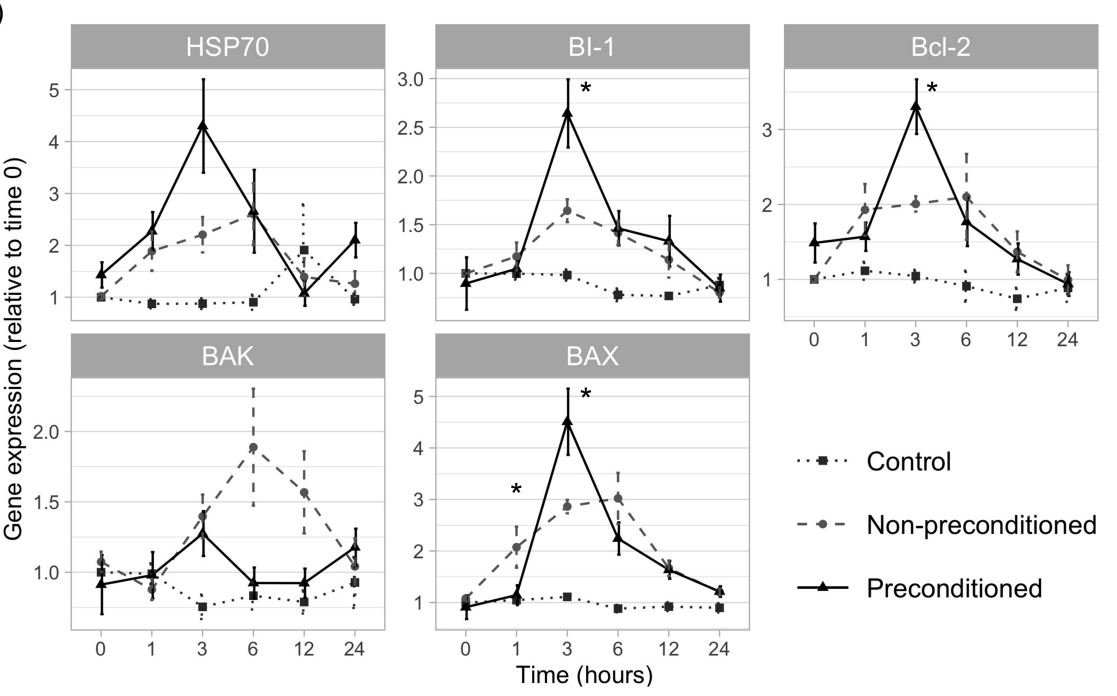

(B)

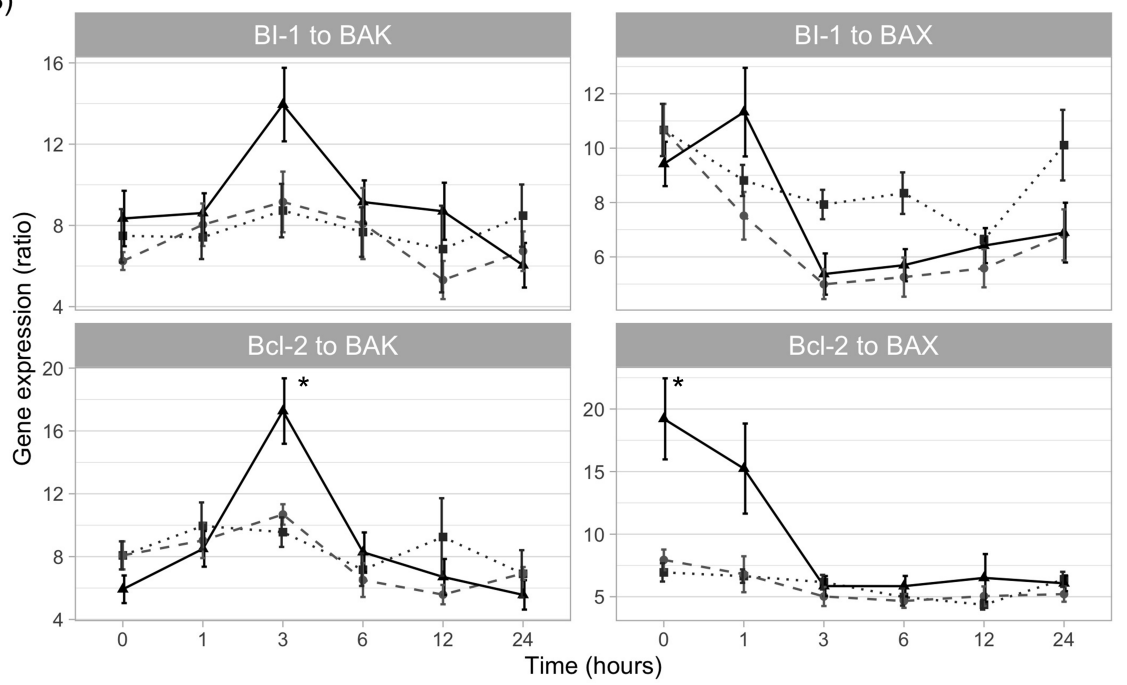

Figure 2 Expression of genes related to bleaching and programmed cell death pathways, relative to control at time $0 \mathrm{~h}$. Control samples are depicted with dark grey dotted line, non-preconditioned (NPC) with light grey dashed line and preconditioned $(\mathrm{PC})$ with black solid line. $\Delta \Delta \mathrm{Ct}$ method was used to calculate the relative expression and the ratios. Graph shows mean values with standard error bars. Oneway ANOVA with Tukey's post hoc test for each timepoint was used to test the difference of the values. * marks significant ( $\mathrm{p}$ [?] 0.05) difference between PC and NPC corals, $\mathrm{n}=10$.

Figure 3 
(A) Correlation of gene expression between PC and WT corals

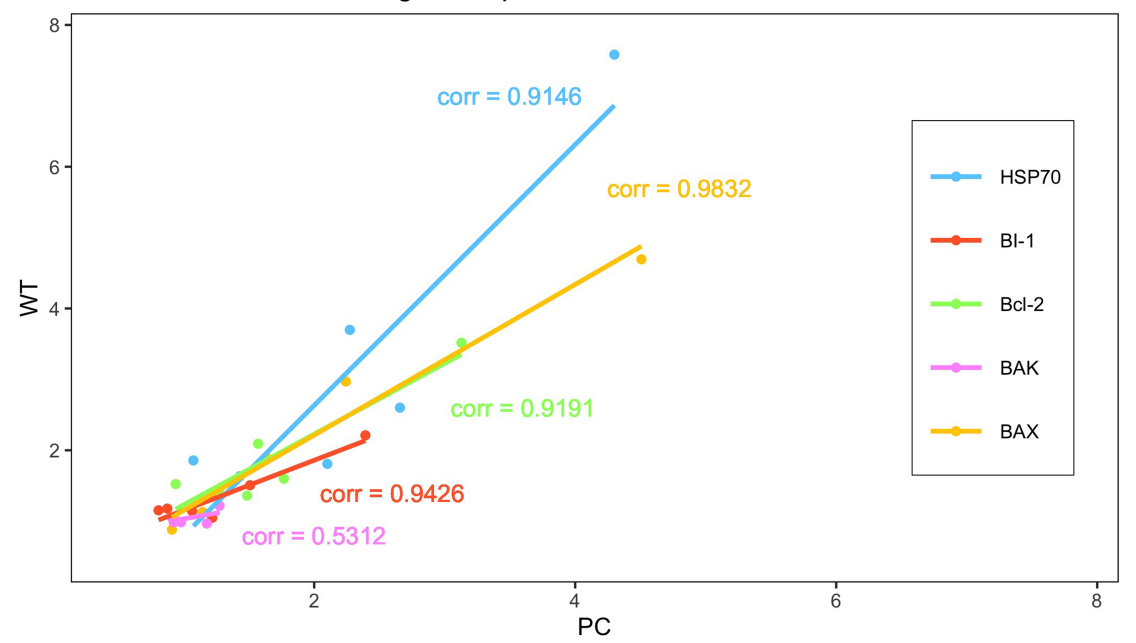

(B)

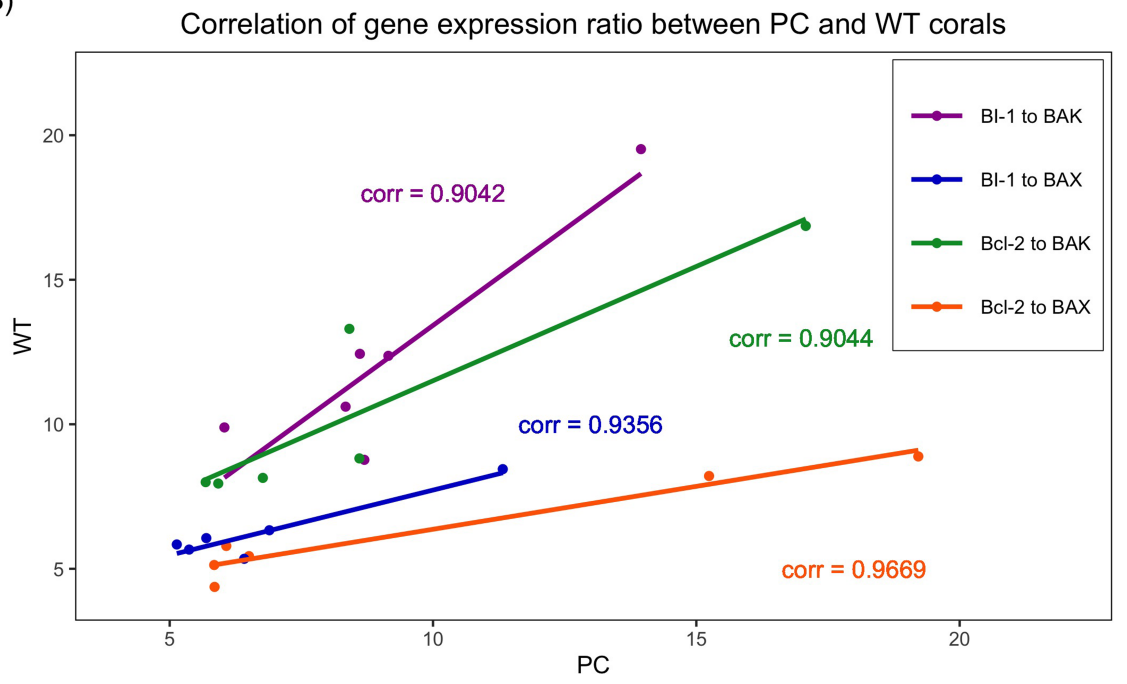

Figure 3 Correlation of gene expression between PC and WT corals during heat stress. Linear regression model with Pearson correlation was calculated for mean single gene expression (A) and mean gene expression ratio (B) of preconditioned (PC) and wild-type (WT) corals during acute heat stress $\left(32^{\circ} \mathrm{C}\right), \mathrm{n}$ $=6$. $\mathrm{PC}$ corals were exposed to three-day sublethal temperature $\left(29^{\circ} \mathrm{C}\right)$ and then rested for two weeks at ambient temperature $\left(26^{\circ} \mathrm{C}\right)$. WT corals were exposed to natural summer fluctuating oceanic temperatures in Kaneohe Bay, Hawaii with peaks around $29^{\circ} \mathrm{C}$. Pearson correlation factors show very similar response to sudden heat stress in both groups of corals pointing to the natural ability of corals to acclimatize to summer temperatures through modulations in the signaling pathways.

Figure 4 
(A)
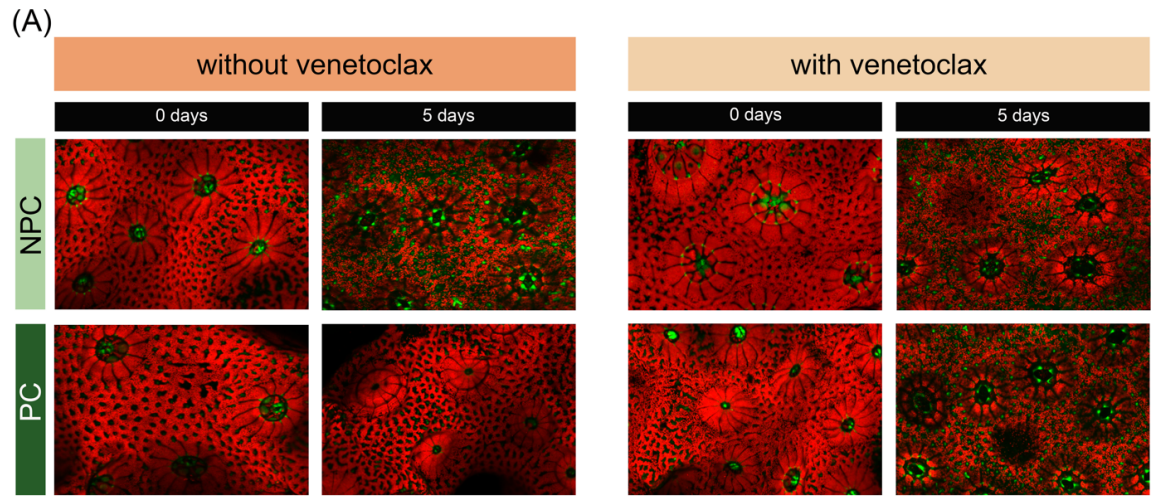

(B)

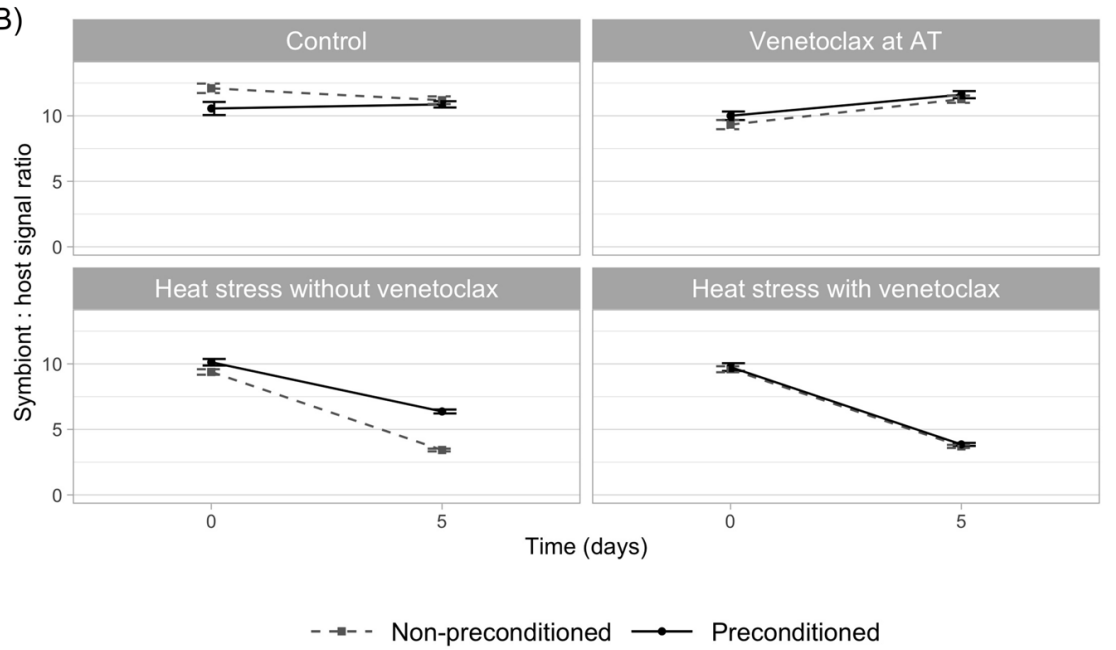

Figure 4 Preconditioned (PC) corals treated with Bcl-2 inhibitor venetoclax lost the more thermal-resilient phenotype and bleached at the same rate as non-preconditioned (NPC) corals. A) Fluorescence confocal microscopy pictures of coral fragments that underwent 5-day long heat stress without or with venetoclax. Host cells are visualized in green, algal cells in red. B) Bleaching rate of PC and NPC corals based on calculating the symbiont: host cells signal ratio. A set of control experiments was designed to rule out the effect of venetoclax itself to coral symbiont density. Multiway ANOVA analysis with Tukey's post hoc test (microscopy_signal ${ }^{\text {time }}{ }^{*}$ conditioning * treatment) was used to test the similarity of bleaching rate. The analysis showed a significant difference in bleaching rate between PC and NPC corals not treated with venetoclax $(\mathrm{p}=0.000)$ but no difference in corals treated with venetoclax $(\mathrm{p}=0.464)$ pointing to the crucial role of $\mathrm{pBcl}-2$ in acclimatization and coral bleaching. Graphs show mean values with standard error bars, $\mathrm{n}=5$.

Figure 5 
(A)

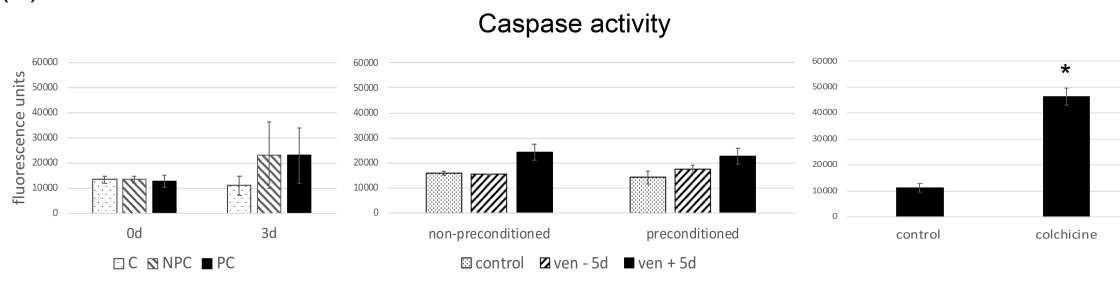

(B)

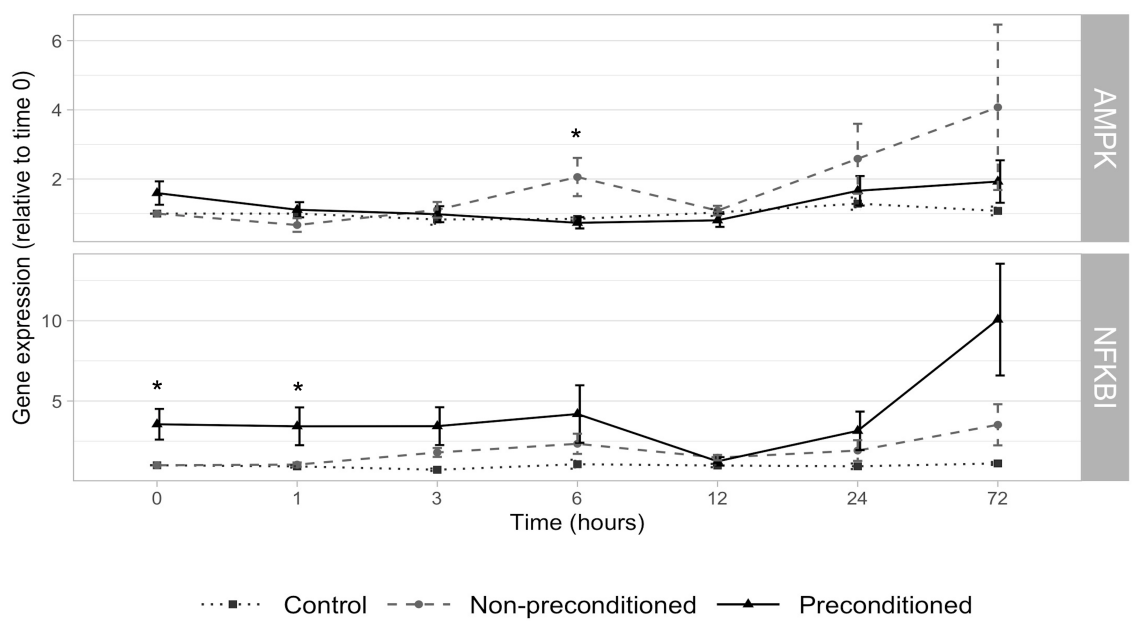

Figure 5 Analyses of programmed cell death pathway point to the prevalent role of symbiophagy (autophagy) in $\boldsymbol{P}$. acuta thermally induced bleaching. A) Caspase-3 activity in NPC and PC corals under different conditions. i) Caspase-3 activity in NPC and PC corals at day 3 of the heat stress. ii) Caspase-3 activity in NPC and PC corals without (dashed lines) and with (black) venetoclax after 5-days long thermal stress compared to control (dotted) corals. iii) Caspase-3 activity in corals treated with apoptosis activator colchicine compared to controls. Error bars represent standard deviations $(\mathrm{n}=4)$. B) Expression of genes related to programmed cell death pathways, relative to control at time 0h. Control samples are depicted with dark grey dotted line, non-preconditioned (NPC) with light grey dashed line and preconditioned (PC) with black solid line. $\Delta \Delta$ Ct method was used to calculate the relative expression and the ratios. Graph shows mean values with standard error bars. * marks significant (p [?] 0.05) difference between PC and NPC calculated using one-way ANOVA with Tukey's post hoc test for each timepoint individually, $\mathrm{n}=10$.

\section{Supplementary Figures}

Figure S1 


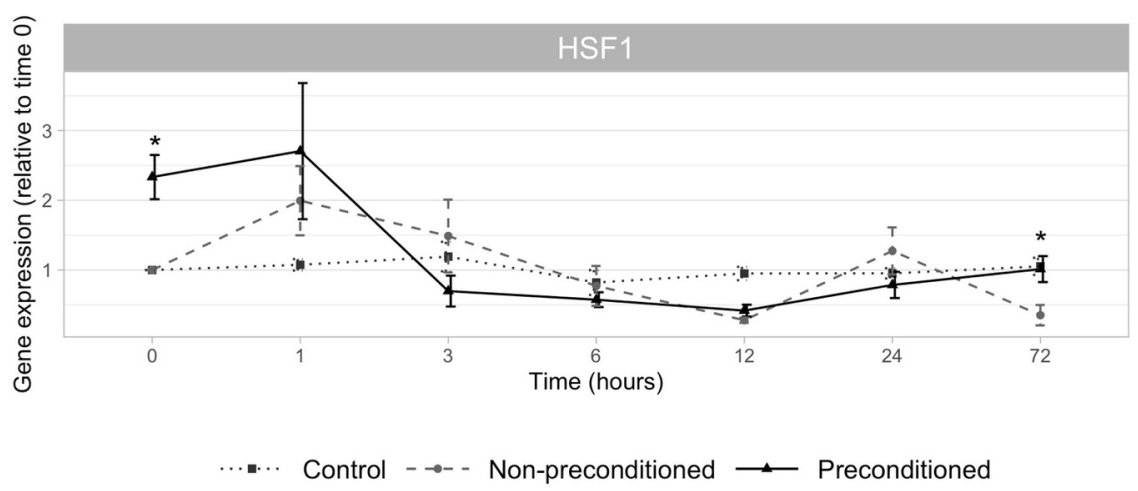

Figure S1 Expression of pHSF1, the major transcription factor of heat shock protein family . Expression of pHSF1 relative to control at time 0h. Control samples are depicted with dark grey dotted line, non-preconditioned (NPC) with light grey dashed line and preconditioned (PC) with black solid line. $\Delta \Delta \mathrm{Ct}$ method was used to calculate the relative expression and the ratios. Graph shows mean values with standard error bars. * marks significant (p [?] 0.05) difference between PC and NPC calculated using one-way ANOVA with Tukey's post hoc test for each timepoint individually, $\mathrm{n}=10$. 
(A)

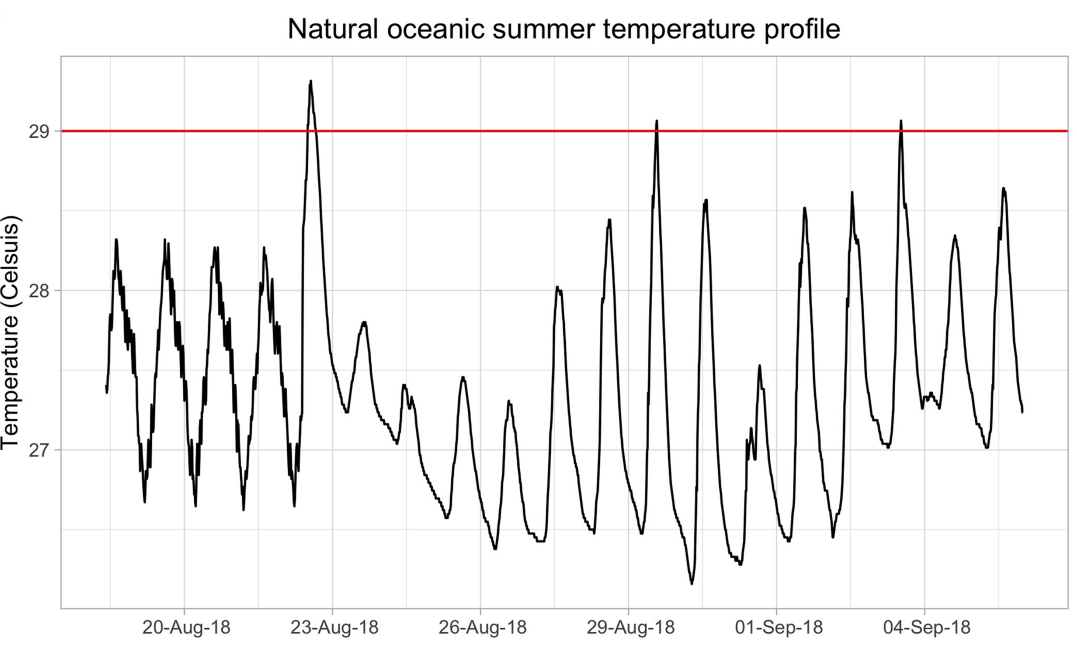

(B)
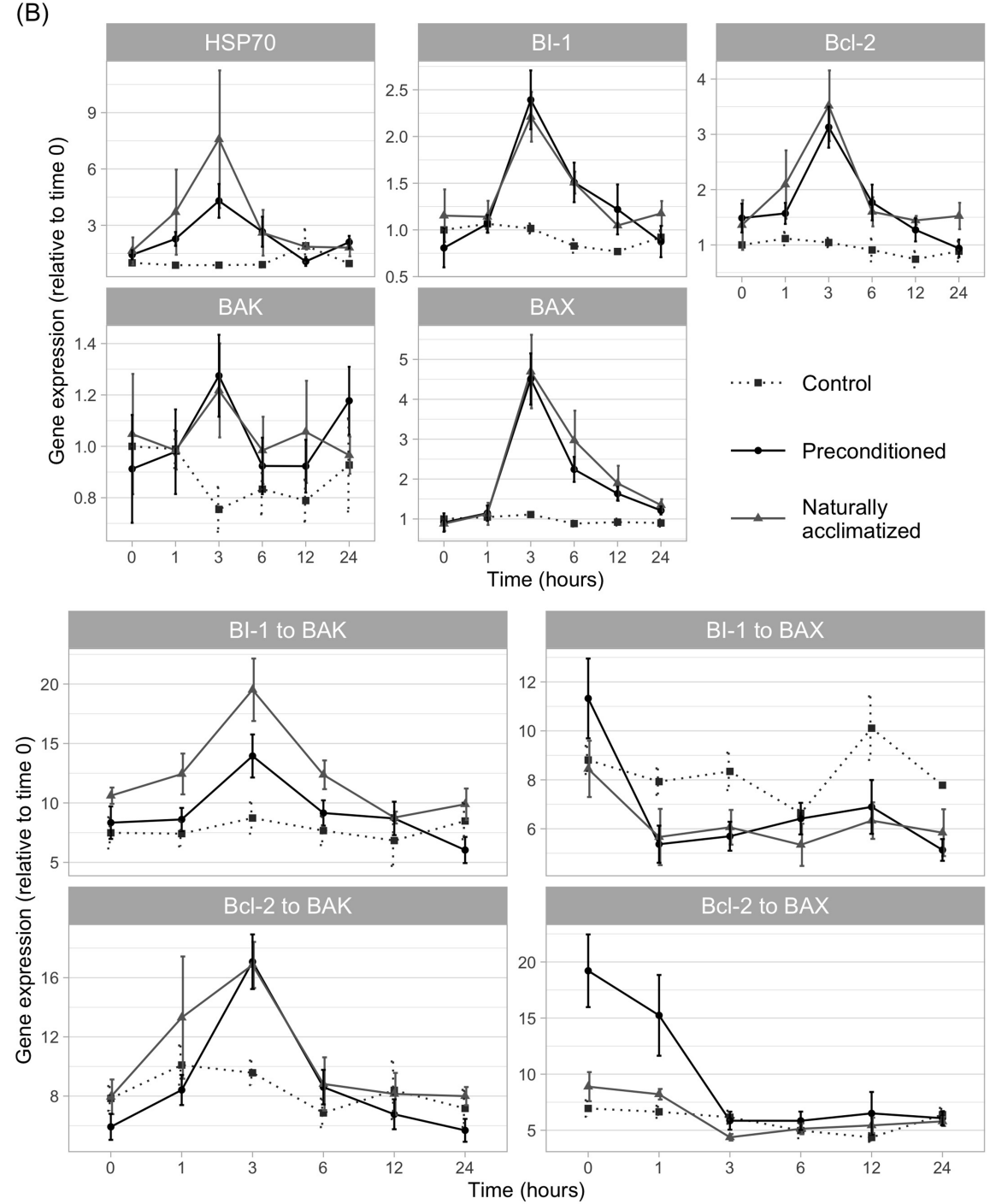


\section{Figure S2}

Figure S2 Corals acclimatized to natural oceanic temperatures show similar gene expression profile than corals preconditioned in labA) Natural oceanic summer temperature profile around Coconut Island, Hawaii, during summer 2018. It shows that corals were naturally exposed to sublethal temperatures several times during the period. B) Gene expression in naturally acclimatized corals (light grey solid line) compared to experimentally preconditioned corals (black solid line) and control corals (dotted dark grey line). $\Delta \Delta \mathrm{Ct}$ method was used to calculate the relative expression and the ratios. Graph shows mean values with standard error bars. $\mathrm{n}=6$

Figure S3
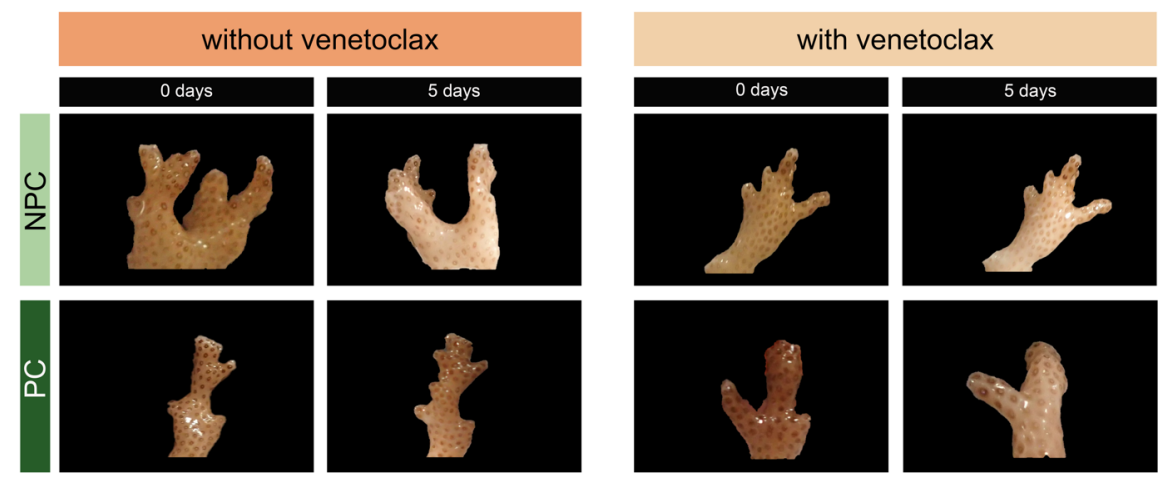

Figure S3 Visualized coral bleaching upon acute heat stress with or without the addition of venetoclax, Bcl-2 inhibitor. Non-preconditioned (NPC) corals bleach in both conditions but preconditioned (PC) corals show acquired higher thermal resilience that is lost after addition of venetoclax. It points to the crucial role of pBcl-2 in coral acclimatization and bleaching.

Table S1 


\begin{tabular}{|c|c|c|c|}
\hline Gene & Full name & & primer sequence \\
\hline \multirow{2}{*}{ pBI-1 } & \multirow{2}{*}{ Bax inhibitor 1} & fwd & 5' TGGACCTCTGATGGACAATGTG 3' \\
\hline & & rev & 5' AAGTTCGTTCCTCTGCCCAC 3' \\
\hline \multirow{2}{*}{ pBAX } & \multirow{2}{*}{ Bcl2 Associated X } & fwd & 5'- GATTATTGGGTGGGTGTGTG -3' \\
\hline & & rev & 5'- CCTGAACATCGTGCTTCTTTC -3' \\
\hline \multirow{2}{*}{ pBcl-2 } & \multirow{2}{*}{ B-cell lymphoma 2} & fwd & 5'- GTTTGATTCCATGTGCGACC -3' \\
\hline & & rev & 5'- ATGCCAGAAACGCCACTATG -3' \\
\hline \multirow{2}{*}{ pBAK } & \multirow{2}{*}{ Bcl2 Antagonist/Killer } & fwd & 5'- AGACGCGCTGGAAGAATTGC -3' \\
\hline & & rev & 5'- GCTGGCGTTAGGCTTAATGAGTC -3' \\
\hline \multirow{2}{*}{ pHSP70 } & \multirow{2}{*}{ heat shock protein 70} & fwd & 5'- TTCCAAGTTCTCTCCACAGC -3' \\
\hline & & rev & 5'- TTCGGGTTGGTCTTGAGATCC -3' \\
\hline \multirow{2}{*}{ pActin } & \multirow{2}{*}{ actin } & fwd & 5'- GGGTGTGATGGTTGGTATGG -3' \\
\hline & & rev & 5'- CGTTGTAGAAGGTGTGATGC -3' \\
\hline \multirow{2}{*}{ pEF-1a } & \multirow{2}{*}{ elongation factor $1 \mathrm{a}$} & fwd & 5'- GCTGTGAACAAGATGGACAC -3' \\
\hline & & rev & 5'- ATGGGAACAAATACCACGGC -3' \\
\hline \multirow{2}{*}{ pCalm } & \multirow{2}{*}{ Calmodulin } & fwd & 5'- GTCCAAGACAGAGGAAGATG -3' \\
\hline & & rev & 5'- ACAGCCCAACAATCTACTGC -3' \\
\hline \multirow{2}{*}{ pAHC } & \multirow{2}{*}{ AdenosylHomoCysteinase } & fwd & 5'- TGCTCGTGTTCTGGTCACTG -3' \\
\hline & & rev & 5'- AAGATCTGTCCCTGTGAGGC -3' \\
\hline \multirow{2}{*}{ pHSF1 } & \multirow{2}{*}{ heat shock factor 1} & fwd & 5' -TCAGCACGTATACCTGCGAG -3' \\
\hline & & rev & 5' -CCACTCGAATCTCCGTCTCC - 5' \\
\hline \multirow{2}{*}{ pNFKBI } & \multirow{2}{*}{$\begin{array}{c}\text { Nuclear Factor Kappa B } \\
\text { inhibitor }\end{array}$} & fwd & 5' - GCCGAACAGCTTTGCACGCC - 3' \\
\hline & & rev & 5' - GCTCTTACATTGGCTCCGTTC - 3' \\
\hline \multirow{2}{*}{ PAMPK } & \multirow{2}{*}{$\begin{array}{c}\text { adenosine monophosphate- } \\
\text { activated protein kinase }\end{array}$} & fwd & 5' - GAATCTCCTTCTGGATGCCC -3' \\
\hline & & rev & 5'- TCGCAGGAATTCACCATCTG -3' \\
\hline \multirow{2}{*}{ pGFP } & \multirow{2}{*}{ Green fluorescent protein } & fwd & 5'- CTTTGAGATCGAAGGTGAAGG -3' \\
\hline & & rev & 5'- GGGTCCTCCCTTGGTTACCC -3' \\
\hline \multirow{2}{*}{ pAPAF-1 } & \multirow{2}{*}{$\begin{array}{c}\text { Apoptotic Peptidase Activating } \\
\text { Factor } 1\end{array}$} & fwd & 5'- GGTTTGGAATGTACAGAGTGG -3' \\
\hline & & rev & 5'- AGCTCTCCGGTGGAAGAATC -3' \\
\hline \multirow{2}{*}{ pCas3 } & Caspase 3 & fwd & 5'- CTTCCAATTTTCGCCGAGATG -3' \\
\hline & & rev & 5'- TCACTGTCGCTCTTGATAGG -3' \\
\hline nBNIP-3 & BCL 2 Interacting Protein 3 & fwd & 5'- TCA ATG GTG GCA GTC ATA GC -3' \\
\hline potvin-s & 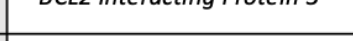 & rev & 5'- GAA TGC TGA GCT CCA TTG CC -3' \\
\hline pSurvivin & Survivin & fwd & 5'- CGGGATCTTGTTGTACTGCG -3' \\
\hline & & rev & 5'- CATCAACAGAATCATTCGCGC -3' \\
\hline pRab7 & Ras-Associated Protein 7 & fwd & 5'- CGG AGG ACT CGG CTA GTG AC -3' \\
\hline proas & 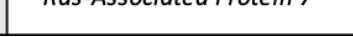 & rev & 5'- AGT GGC GTG AAA CGA TGC GG -3' \\
\hline
\end{tabular}

Table S1 Primer sequences used for RT-qPCR experiments 